\title{
Effect of Venturi System on Acceleration of Low-speed Water Flow at the Venturi Throat Installed at the Inlet of Hydro Turbine
}

\author{
Sang-Hoon Jung $^{1} \cdot \mathrm{In}^{-} \mathrm{Ho} \mathrm{Seo}^{2} \cdot$ Chul-Ho $\mathrm{Kim}^{\dagger}$ \\ (Received October 25, 2011; Revised Novermber 4, 2011; Accepted November, 14, 2011)
}

\begin{abstract}
For a hydro turbine electricity generation system in river or bay, a venturi system could be applied to accelerate flow speed at the inlet of the turbine system in a flow field. In this study, a steady flow simulation was conducted to understand the effect of venturi system on the acceleration of current speed at the inlet of a hydro turbine system. According to the continuity equation, the flow speed is inversely proportional to the cross-section area in a conduit flow; however, it would be different in an open region because the venturi system would be an obstruction in the flow region.

As the throat area is $1 / 5$ of the inlet area of the venturi, the flow velocity is accelerated up to 2.1 times of the inlet velocity. It is understood that the venturi system placed in an open flow region gives resistance to the upcoming flow and disperses the flow energy around the venturi system. The result of the study should be very important information for an optimum design of a hydro turbine electricity generation system.
\end{abstract}

Key words : venturi system, hydro turbine electricity generation system, Computational Fluid Dynamics(CFD), hydro power turbine, open channel flow

\section{Introduction}

Due to global warming and limitation of clued oil problem people has been seriously studied to have a solution. One of the representative renewable energy sources can be obtained from ocean and those are the current energy, wave energy, coastal wind power energy and et al. Among them, the current energy is less affected by the weather condition in nature but the energy conversion efficiency is low when current speed slow in a current electricity generation station. Because of this reason, a venturi system can be applied to accelerate the current flow in low speed to have higher efficiency of current electricity generation system.

In this numerical study, an acceleration effect of a venturi system that would be applied to a hydro electricity generation system in a open-channel was studied. Two main design parameters; area ratio $\left(\mathrm{R}_{\mathrm{A}}\right)$ and blockage ratio $\left(\mathrm{R}_{\mathrm{B}}\right)$, were incorporated to understand their effects on the flow speed acceleration at the inlet of the electricity generation system.

\section{Geometry of the Open-channel and Venturi System for Numerical Study}

Figure 1 shows configuration and its dimension of the model open-channel to see the effect of the

\footnotetext{
† Corresponding Author(Department of Automotive Engineering, Seoul National University of Science \& Technology, Korea, E-mail: hokim@seoultech.ac.kr, Tel: +82-2-970-6347)

1,2. Seoul National University of Science \& Technology Graduate School of NID Fusion Technology, Korea

This paper is extended and updated from the short version that apeared in the Proceedings of the International symposium on Marine Engineering and Technology (ISMT 2011), held at BEXCO, Busan, Korea on October 25-28, 2011.
} 
model venturi system installed in it. The length and depth of the channel were fixed to $600 \mathrm{~m}$ and $10 \mathrm{~m}$ respectively but the width was varied from $15 \mathrm{~m}$ to $110 \mathrm{~m}$ to see the blockage effect of the model venturi system (the width is fixed $10 \mathrm{~m}$.) in the flow field.

Figure 2 is the top view of the model open-channel with the model venturi system placed the wall-side and $100 \mathrm{~m}$ downstream from the inlet. The length and width of the model venturi-system were fixed to $50 \mathrm{~m}$ and $10 \mathrm{~m}$ respectively but the throat width of the venturi was varied from $2 \mathrm{~m}$ to $6 \mathrm{~m}$ to understand the acceleration effect of the flow in the throat.

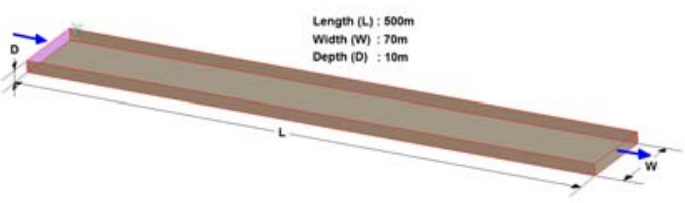

Figure 1: Physical domain of the model flow field : $500 \mathrm{~m}(\mathrm{~L}) \times 70 \mathrm{~m}(\mathrm{~W}) \times 10 \mathrm{~m}(\mathrm{D})$

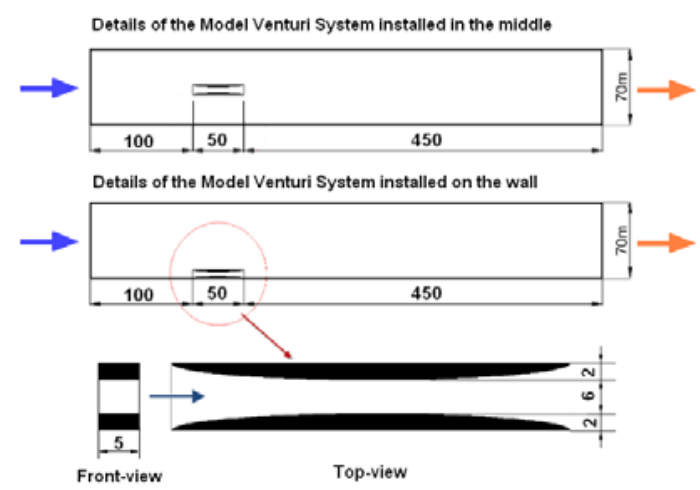

Figure 2: Top view of the model open-channel with the model venturi system (Model-1) installed in the middle and on the wall side of the flow field

The flow field is extended 450m backward from the exit of the venturi system to have fully developed flow in the numerical domain.

\section{Numerical Scheme and Its Condition}

In this numerical study, a venturi system has been tested to understand the availability of the system to speedup the flow velocity in a flow field.

\subsection{Important Geometry Variables of the Model Venturi System}

Area ratio $\left(\mathrm{R}_{\mathrm{A}}\right)$ and blockage ratio $\left(\mathrm{R}_{\mathrm{B}}\right)$ are the two main parameters in this study to see their effects on the acceleration of the flow in the throat of the model venturi system.

$$
\begin{aligned}
& \text { - Area Ratio( }\left(R_{A}\right): \mathbf{R}_{A}=\mathbf{A}_{\mathbf{t}} / \mathbf{A}_{\mathbf{v}} \\
& \text { - Blockage Ratio( }\left(R_{B}\right): \mathbf{R}_{\mathbf{B}}=\mathbf{A}_{\mathbf{v}} / \mathbf{A}_{\text {in }}
\end{aligned}
$$

As shown in Table 1 , the area ratio was varied from 0.2 to 0.6 in 3 steps and the blockage ratio $\left(\mathrm{R}_{\mathrm{B}}\right)$ was varied from $4.6 \%$ to $33.3 \%$ in 6 steps with Model-3 $\left(\mathrm{R}_{\mathrm{A}}=0.2\right)$.

Table 1: Important geometry variables of the

\begin{tabular}{|c|c|c|c|}
\hline & & & (unit: $\mathrm{m}$ ) \\
\hline & $\begin{array}{c}\text { Model } \\
\text { geometry }\end{array}$ & $\begin{array}{c}\text { Area } \\
\text { ratio }\left(\mathbf{R}_{\mathbf{A}}\right)\end{array}$ & $\begin{array}{l}\text { Blockage } \\
\text { ratio( }\left(\mathbf{R}_{\mathbf{B}}\right)\end{array}$ \\
\hline Model-1 & $\begin{array}{l}a-w_{t}-a \\
2-6-2\end{array}$ & 0.6 & \\
\hline Model-2 & $\begin{array}{l}a-w_{t}-a \\
3-4-3\end{array}$ & 0.4 & $7.1 \sim 34 \%$ \\
\hline Model-3 & $\begin{array}{c}a-w_{t}-a \\
4-2-4\end{array}$ & 0.2 & \\
\hline Remarks & \multicolumn{3}{|c|}{$\begin{array}{l}A_{t}=h_{v} \times W_{t}, \quad A_{v}=h_{v} \times W_{v} \\
A_{\text {in }}=h_{\text {in }} \times W_{\text {in }}\end{array}$} \\
\hline
\end{tabular}
model venturi system 


\subsection{Numerical Scheme of Flow Analysis}

In this study, FVM (Finite Volume Method) [1] scheme was employed to simulate flow phenomenon around a model venturi system in the open-channel. The water flow field in the control volume is reasonably assumed to be,

- Full 3D flow,

- Turbulent flow,

- Incompressible flow,

- Steady state flow.

The general-purpose CFD code, PHOENICS [2] (ver. 2009) was used for a numerical calculation of the turbulent incompressible flow field. 3-dimensional Navier-Stokes equations [3] were solved with standard (k- $\mathrm{k})$ turbulent model [4]. Since the process was assumed as steady state and adiabatic process, the energy equation was not required to be solved in the numerical calculation. The laminar no-slip condition near solid boundary was modeled by the logarithmic law. Time differencing has been fully implicit backward while advection terms are hybrid differenced. Conjugate gradient technique for pressure corrections in transport equations has been incorporated and 'SIMPLE' algorithm [4] has been employed for the velocity and pressure coupling in this application. For the convergence of the numerical solution, the iteration was continued until the residual fraction was below $1 \times 10^{-4}$.

\subsection{Governing Equations}

The basic equations of fluid dynamics in the control volume are based on Navier-Stokes equations [3] that are comprised of equations for conservation of mass and momentum and given as,

(1) Continuity equation

$$
\frac{\partial U_{i}}{\partial x_{i}}+\frac{\partial U_{j}}{\partial y_{i}}+\frac{\partial U_{k}}{\partial z_{i}}=0
$$

(2) Momentum equation

$$
\frac{\partial U_{i}}{\partial t}+\frac{\partial}{\partial x_{j}}\left(U_{i} U_{j}\right)=-\frac{1}{\rho} \frac{\partial P}{\partial x_{i}}+\frac{\partial}{\partial x_{j}}\left[v\left(\frac{\partial U_{i}}{\partial x_{j}}+\frac{\partial U_{j}}{\partial x_{i}}\right)-\overline{u_{i} u_{j}}\right]-g_{i}
$$

(3) Standard $\kappa-\varepsilon$ turbulent model

- Turbulent kinetic energy equation

$$
\frac{\partial}{\partial x_{i}}\left(U_{j} k\right)=\frac{\partial}{\partial x_{i}}\left[\left(v+\frac{v_{t}}{\sigma_{k}}\right) \frac{\partial k}{\partial x_{j}}\right]+G-\varepsilon
$$

- Energy dissipation equation

$$
\begin{aligned}
\frac{\partial}{\partial x_{i}}\left(U_{j} \varepsilon\right) & =\frac{\partial}{\partial x_{i}}\left[\left(v+\frac{v_{t}}{\sigma_{\varepsilon}}\right) \frac{\partial \varepsilon}{\partial x_{j}}\right]+\frac{\varepsilon}{k}\left(C_{\varepsilon 1} G-C_{\varepsilon 2} \varepsilon\right) \\
-\overline{u_{i} u_{j}} & =v_{t}\left(\frac{\partial U_{i}}{\partial x_{j}}+\frac{\partial U_{j}}{\partial x_{i}}\right)-\frac{2}{3} k \delta_{i j}
\end{aligned}
$$

$$
G=-\overline{u_{i} u_{j}} \frac{\partial U_{i}}{\partial x_{j}} \quad v_{t}=C_{\mu} \frac{k^{2}}{\varepsilon}
$$

$$
\left(C_{\mu}=0.09 \quad C_{\varepsilon 2}=1.92 \quad C_{\varepsilon 1}=1.94 \quad \sigma_{k}=1.0 \quad \sigma_{\varepsilon}=1.0\right)
$$

\subsection{Numerical Grid of Physical Model and Its Conditions}

The CAD-to-CFD method (CHAM, 2009) [2] in conjunction with orthogonal grids [5] was incorporated for the numerical grid generation in the physical domain in this study. First, a 3-dimensional geometry of the model channel and venturi were modeled by Pro-Engineers, a 3-dimensional CAD software and transferred the models into to the numerical domain to generate the numerical grids in the rectangular coordinate system.

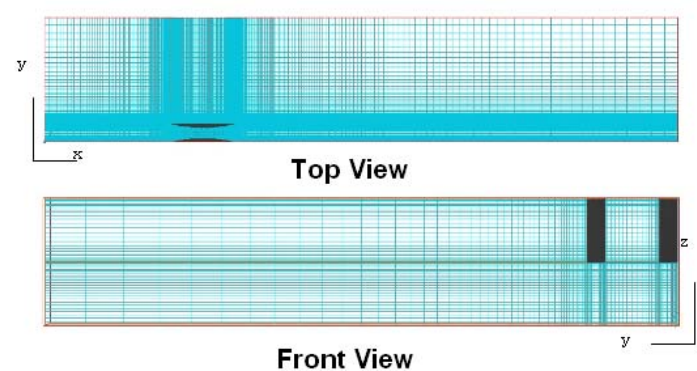

Figure 3: A typical 3-D numerical grad of the open channel with the model venturi (Model-1) 
Figure 3 shows a typical numerical domain with the model open-channel with a model venturi (Model-1) incorporated for this numerical study. The optimum grid size of the 3-D model was decided to $(131 \times 26 \times 38)$ from the prior validation test of numerical grid.

\section{(Boundary and Initial Conditions)}

(1) Velocity boundary condition at the inlet of the control volume; $V_{\text {in }}=0.5 \sim 4.0 \mathrm{~m} / \mathrm{s}$

(2) Constant pressure boundary condition at the exit of the control volume

(3) No-slip condition on the surface of the model channel and venturi system

(4) Potential flow conditions on the open surface of the control volume; top and bottom sides of the channel

\section{Results and Discussion}

In this numerical study, the effect of venturi system for the acceleration of flow speed of water at the venturi throat was studied with the change of the area ratio $\left(\mathrm{R}_{\mathrm{A}}\right)$ and blockage ratio $\left(\mathrm{R}_{\mathrm{B}}\right)$ of the flow system. The simulation results were analyzed such as,

- Variation of Flow Speed $\left(V_{t}\right)$ at Throat of the Model Venturi with Area Ratio $\left(\mathrm{R}_{\mathrm{A}}\right)$

- Variation of Flow Speed $\left(\mathrm{V}_{\mathrm{t}}\right)$ at Throat of the Model Venturi with Blockage Ratio $\left(\mathrm{R}_{\mathrm{B}}\right)$

- Variation of Flow Speed $\left(\mathrm{V}_{\mathrm{t}}\right)$ at Throat of the Model Venturi with Location of the Model Venturi

\subsection{Flow Characteristics in the Flow Field with RA and $\mathrm{RB}$}

(1) Effect of the Area Ratio $\left(\mathrm{R}_{\mathrm{A}}\right)$ on the Throat Velocity $\left(\mathrm{V}_{\mathrm{t}}\right)$

The throat velocity $\left(\mathrm{V}_{\mathrm{t}}\right)$ and the flow characteristics around the model venturi system with the change of throat area $\left(A_{t}\right)$ were analyzed at $\mathrm{R}_{\mathrm{B}}=7.1 \%$.
As shown in Figure 4, the throat velocity $\left(\mathrm{V}_{\mathrm{t}}\right)$ increases as the throat area decreases but the recirculation zone increases as well at the exit of the venturi because the flow resistance increases with the thickness of venturi wall and the separation point moves forward due to viscosity effect on the wall. The recirculation zone will have strong resistance on the exit flow in the system.

(2) Effect of the Blockage Ratio $\left(R_{B}\right)$ on the Throat Velocity $\left(\mathrm{V}_{\mathrm{t}}\right)$

Figure 5 shows the effect of $R_{B}$ on the $V_{t}$ at the constant $R_{A}(=2.0)$. As the $R_{B}$ increases, the $V_{t}$ increases as well because the momentum energy passing through the throat increases as well. However, the separation position does not change much in all cases. It means that the flow pattern depends more on the convergent-divergent shape of the venturi system not on the momentum energy level passing through the venturi system.

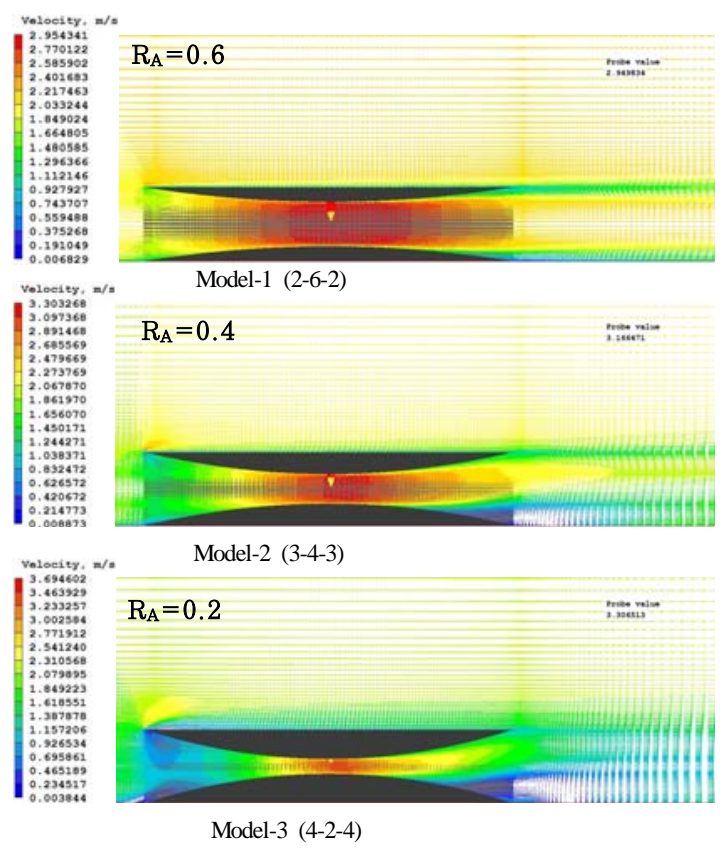

Figure 4: Variation of water flow speed at the throat with the throat width at constant blockage ratio $\left(\mathrm{R}_{\mathrm{B}}=7.1 \%\right): \mathrm{V}_{\text {in }}=2.0 \mathrm{~m} / \mathrm{s}$. 

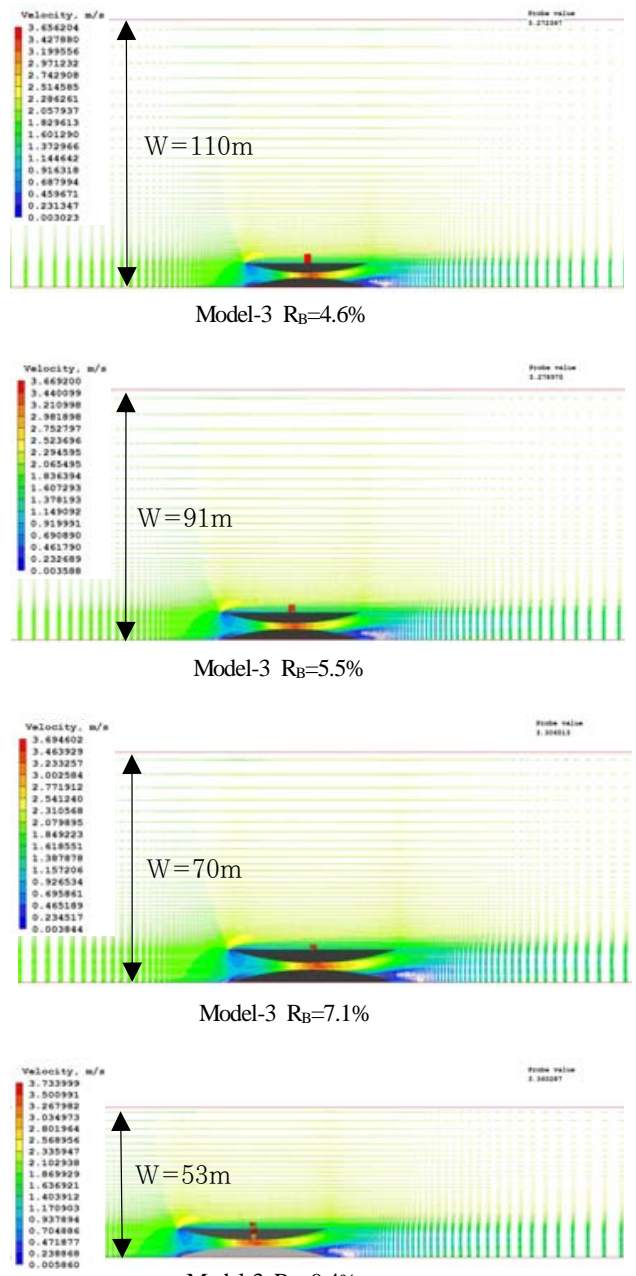

Model-3 $\mathrm{R}_{\mathrm{B}}=9.4 \%$
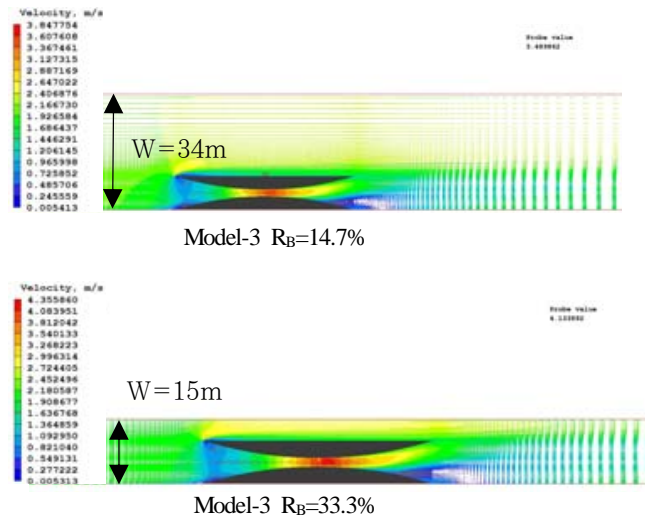

Figure 5: Variation of the water flow speed at the throat with the blockage ratio at constant area ratio $\left(\mathrm{R}_{\mathrm{A}}=0.2\right)$ and $\mathrm{V}_{\mathrm{in}}=2.0 \mathrm{~m} / \mathrm{s}$
4.2 Variation of Throat Velocity (Vt) with Inlet Flow Velocity(Vin)

Figure 6 shows variation of throat velocity $\left(V_{t}\right)$ with inlet velocity $\left(\mathrm{V}_{\mathrm{i}}\right)$ at each different area ratio $\left(\mathrm{R}_{\mathrm{A}}\right)$. As shown in the figure, the throat velocity is higher as the area ratio is lower. It means that the throat velocity is faster as the flow passes through smaller area. This analytical result will be very important information for the optimum design of hydro electricity generation system.

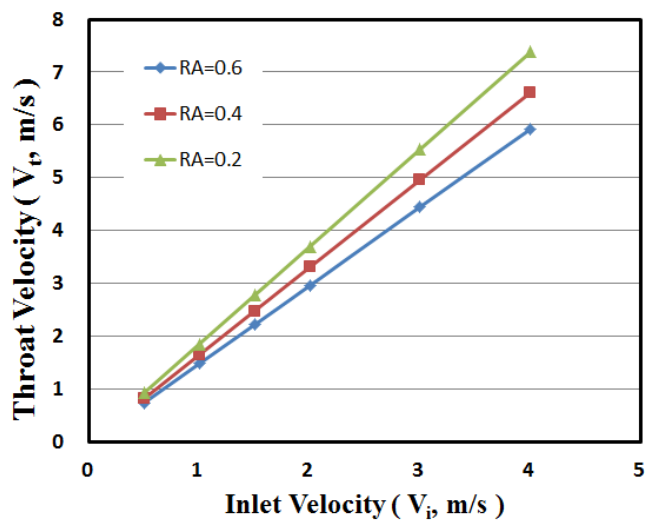

Figure 6: Variation of the velocity ratio $\left(\mathrm{V}_{\mathrm{t}} / \mathrm{V}_{\mathrm{i}}\right)$ with inlet velocity $\left(\mathrm{V}_{\mathrm{t}}\right)$ at $\mathrm{R}_{\mathrm{B}}=7.1 \%$

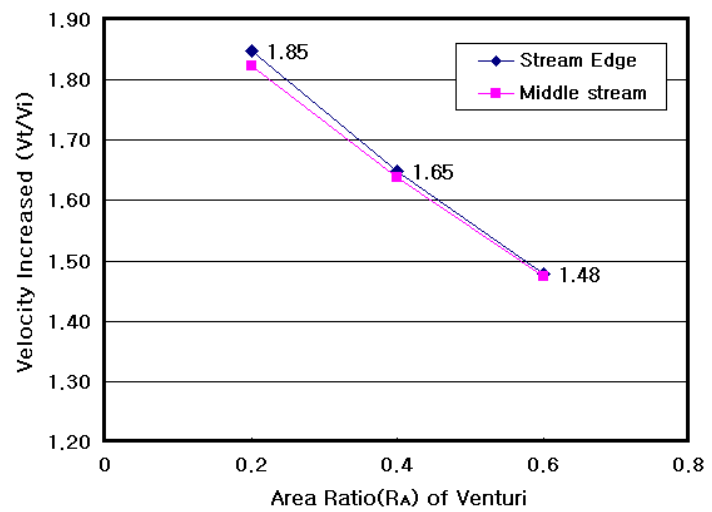

Figure 7: Variation of the velocity ratio $\left(\mathrm{V}_{\mathrm{t}} / \mathrm{V}_{\mathrm{i}}\right)$ with area ratio $\left(\mathrm{R}_{\mathrm{A}}\right)$ at $\mathrm{R}_{\mathrm{B}}=7.1 \%$

Figure 7 shows the variation of the velocity ratio $\left(\mathrm{V}_{\mathrm{t}} / \mathrm{V}_{\mathrm{i}}\right)$ with area ratio $\left(\mathrm{R}_{\mathrm{A}}\right)$ at $\mathrm{R}_{\mathrm{B}}=7.1 \%$ and the 
effect of location where the venturi system is placed in the channel. As shown in the figure, the smaller the area ratio is, the higher the velocity increased ratio. The throat velocity is 1.85 times increases as the throat area is reduced $1 / 5$ of the inlet area of the venturi system. For the effect of the location of the venturi system, when the system is placed at the wall side of the channel, the throat velocity is a bit higher than at the center of the channel. It is due to the flow energy dissipation in the flow field.

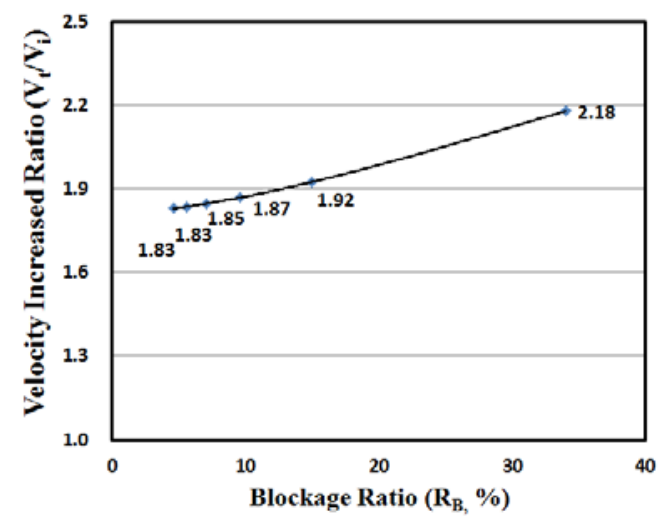

Figure 8: Variation of velocity ratio $\left(V_{t} / V_{i}\right)$ with the blockage ratio $\left(R_{B}\right)$ at $R_{A}=0.2$

Figure 8 shows the variation of velocity ratio with the blockage ratio $\left(R_{B}\right)$. As the blockage is increasing, the throat velocity $\left(\mathrm{V}_{\mathrm{t}}\right)$ increases as well. When the blockage ratio is $30 \%$, the throat velocity increases up to twice of the inlet velocity.

\section{Conclusions}

In this study, an effect of venturi system installed at the inlet of a current electricity generation system to maximize the efficiency of the electricity generation system has been studied. The important design parameters of the venturi system are the area ratio $\left(R_{A}\right)$ and blockage ratio $\left(R_{B}\right)$ of the venturi system. An effect of location of the venturi system in the open-channel was also analyzed to understand the velocity acceleration effect in the throat. The following results would be very valuable information for the optimum design of venturi system installed at the inlet of hydro power generation system in future.

(1) The Relationship between Throat Flow Velocity $\left(V_{t}\right)$ and Area Ratio $\left(R_{A}\right)$ of the Venturi System

The continuity equation can not be applied to the venturi throat in an open-channel to evaluate the flow velocity at the throat of a venturi system. It was found that the throat velocity is not inversely proportional to the throat area; however, Eq. (5) is a valuable analytical equation to estimate throat velocity of a venturi system with the inlet stream velocity $\left(\mathrm{V}_{\text {in }}\right)$.

$$
\left(\mathrm{V}_{\mathrm{t}} / \mathrm{V}_{\text {in }}\right)=0.375 \mathrm{R}_{\mathrm{A}}{ }^{2}-1.225 \mathrm{R}_{\mathrm{A}}+2.08
$$

(2) The Relationship between Throat Flow Velocity $\left(\mathrm{V}_{\mathrm{t}}\right)$ and Blockage Ratio $\left(\mathrm{R}_{\mathrm{B}}\right)$ of the Venturi System

Blockage ratio $\left(R_{B}\right)$ is another important parameter affecting to throat velocity $\left(\mathrm{V}_{\mathrm{t}}\right)$ of the venturi system in a open-channel flow. As blockage ratio $\left(R_{B}\right)$ increases, the throat velocity increases as well. Eq. (6) is an analytical equation from the numerical simulation showing the relationship between blockage $\left(R_{B}\right)$ and the velocity ratio $\left(\mathrm{V}_{\mathrm{t}} / \mathrm{V}_{\mathrm{in}}\right)$. It is also very important information for the optimum design of the inlet venturi system of hydro electricity generation system.

$$
\left(\mathrm{V}_{\mathrm{t}} / \mathrm{V}_{\mathrm{in}}\right)=0.0001 \mathrm{R}_{\mathrm{B}}^{2}+0.0063 \mathrm{R}_{\mathrm{B}}+1.7948
$$

(3) An Effect of the Location of the Venturi System in the Flow Field.

The location of the venturi system in a open-channel flow field does not have serious effect on the throat velocity of a venturi system. 


\section{References}

[1] Douglas, J. F., et al, Fluid Mechanics, Prentice Hall, pp. 406-447, 2001.

[2] PHOENICS PIL Manual, Version 2009, CHAM Ltd., 2009.

[3] Y. A.Cengel and J. M.Cimbala, Fluid Mechnaics Fundamentals and Applications, McGraw-Hill International, 2nd edition, pp. 472-476, 2009.

[4] S. V. Patankar, Numerical Heat Transfer and Fluid Flow, Hemisphere Publishing Corp., 1980.

[5] R. L. Thompson, Body Fitted Coordinate, John Wiley \& Sons, Inc., 1991.

\section{Author Profile}

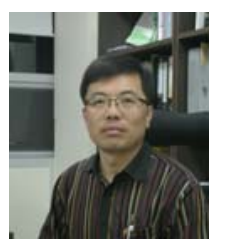

\section{Sang-Hoon Jung}

He received his B.E., M.E. degree in Precision Mechanical Engineering from Seoul National University of Science and Technology (Korea) in 2001 and 2003, and enrolled in Ph.D degree in Nano IT Fusion Program from The Seoul National University of Science \& Technology. He is currently a adjunct professor at the department of automobile engineering in Seoil University. His research interests are Industrial engines and electronic control algorithms and devices.

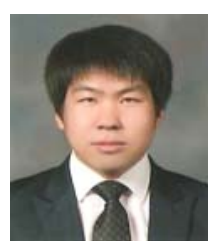

\section{In-Ho Seo}

He received his B.E. degree in Automotive Engineering from Seoul National University of Science and Technology (Korea) in 2010. He is currently enrolled Master's degree program at the Nano IT Fusion Program in Seoul National University of Science \& Technology. His research interests are renewable energy, and its applications.

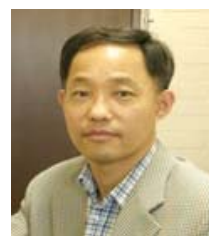

\section{Chul-Ho Kim}

He received his B.E., M.E. degree in Aeronautical Engineering from Inha University (Korea) in 1980 and 1982 and Ph.D degree in Mechanical Engineering from The University of New South Wales, Australia in 1995. He is currently a professor at the department of automotive engineering in Seoul National University of Science \& Technology.

His research interests are Power Train Design of an Electric Vehicle, Turbo-machine Design and Its Performance Analysis, Automotive Aerodynamics and CFD Applications. 